\title{
Constraining ecosystem processes from tower fluxes and atmospheric profiles
}

\author{
T. C. Hill, ${ }^{1,3}$ M. Williams, ${ }^{1}$ F. I. Woodward, ${ }^{2}$ and J. B. MoncriefF ${ }^{1}$ \\ ${ }^{1}$ School of GeoSciences and NERC Centre for Terrestrial Carbon Dynamics, University of Edinburgh EH9 3JN United Kingdom \\ ${ }^{2}$ Department of Animal and Plant Sciences and NERC Centre for Terrestrial Carbon Dynamics, \\ University of Sheffield S10 2TN United Kingdom
}

\begin{abstract}
The planetary boundary layer (PBL) provides an important link between the scales and processes resolved by global atmospheric sampling/modeling and site-based flux measurements. The PBL is in direct contact with the land surface, both driving and responding to ecosystem processes. Measurements within the PBL (e.g., by radiosondes, aircraft profiles, and flask measurements) have a footprint, and thus an integrating scale, on the order of $\sim 1$ $100 \mathrm{~km}$. We use the coupled atmosphere-biosphere model (CAB) and a Bayesian data assimilation framework to investigate the amount of biosphere process information that can be inferred from PBL measurements.

We investigate the information content of PBL measurements in a two-stage study. First, we demonstrate consistency between the coupled model (CAB) and measurements, by comparing the model to eddy covariance flux tower measurements (i.e., water and carbon fluxes) and also PBL scalar profile measurements (i.e., water, carbon dioxide, and temperature) from Canadian boreal forest. Second, we use the CAB model in a set of Bayesian inversions experiments using synthetic data for a single day. In the synthetic experiment, leaf area and respiration were relatively well constrained, whereas surface albedo and plant hydraulic conductance were only moderately constrained. Finally, the abilities of the PBL profiles and the eddy covariance data to constrain the parameters were largely similar and only slightly lower than the combination of both observations.
\end{abstract}

Key words: aircraft observations; boreal forest; BOREAS; carbon budget; ecosystem model; eddy covariance; planetary boundary layer; productivity; transpiration.

\section{INTRODUCTION}

Determining the response of ecosystem processes to climate is critical for predicting future changes in the carbon (C) cycle. Currently two broad methodologies ("top-down" and "bottom-up") are used to constrain C flux estimates, and to improve the understanding of the biogeophysical and biogeochemical processes behind them (Running et al. 1999). Top-down approaches, such as Earth-observation driven models, e.g., CASA (Potter et al. 1993), and inversion models (e.g., Keeling and Heimann 1986, Denning et al. 1995, Bousquet et al. 1999), are used to infer C sources and sinks from either satellite reflectance observations/products or the global network of flask data. These top-down processes are limited by their spatial resolution and their inability to directly determine ecosystem states or processes. Bottomup approaches use eco-physiological and/or micrometeorological measurements, e.g., from FLUXNET (Baldocchi et al. 2001) that directly measure ecosystems

Manuscript received 13 May 2009; revised 25 February 2010; accepted 30 March 2010. Corresponding Editor: D. S. Schimel. For reprints of this Invited Feature, see footnote 1, p. 1427.

${ }^{3}$ E-mail: thill@staffmail.ed.ac.uk states and/or processes. However these bottom-up approaches are spatially limited by the number of global sampling locations, and only sample a limited "footprint" of a few hectares around the study site.

Existing between the global and site scales, the landscape-scale (multiple square kilometers) is increasingly being studied using aircraft (Macatangay et al. 2008 ) with the aim of quantifying land-atmosphere exchanges over areas larger than those monitored by eddy covariance (EC) towers (Owen et al. 2007). Operating on the landscape-scale can help minimize the effect of advection, which is critical in continental or global inversions, but nontrivial to incorporate. This approach can be achieved by using short (several hour) time periods with low winds to limit the spatial advection of the air mass in question to the area of study. Advection problems have been directly addressed using Lagrangian transport models, e.g., the stochastic time-inverted Lagrangian transport model (STILT; Lin et al. 2003) and the NOAA Air Resources Laboratory hybrid single-particle Lagrangian integrated trajectory (HYSPLIT; Draxier and Hess 1998). These models simulate the turbulence in the atmosphere as a Markov chain to estimate source or sink locations and have 
demonstrated the potential to constrain estimates of regional $\mathrm{CO}_{2}$ fluxes using aircraft $\mathrm{PBL}$ measurements (Lin et al. 2004, Martins et al. 2009). However the use of Lagrangian trajectory modeling is numerically expensive and precludes their use in inversions of PBL measurements to infer information about the state of the land surface.

Our objective in this paper is to compare the potential information on ecosystem processes that can be extracted by inverting atmospheric PBL observations relative to inverting surface EC fluxes. We can thus determine the utility of data from different observations systems in constraining ecosystem states in landscapescale inversion problems. To achieve this we implement a coupled atmosphere-biosphere (CAB) model (Hill et al. 2008) both on its own and as part of a Bayesian inversion scheme (Mosegaard and Tarantola 1995, Knorr and Kattge 2005). We drive the model in the normal "forward" mode using multi-scale data from the Boreal Ecosystem-Atmosphere Study (BOREAS; Sellers et al. 1997). This data set provides a wealth of ecological and atmospheric data with which to parameterize and test the model. The large study areas of BOREAS help to minimize the effects of advection without resorting to numerically expensive Lagrangian trajectory modeling. Using this setup we undertook two modeling exercises. The first, called "study 1," was a forward model test of CAB against independent flux and profile data. The second, called "study 2," implemented the CAB model in a Bayesian inversion scheme to determine parameter retrieval from synthetic data sets with known "true" parameters.

We show that the coupled model can successfully reproduce observed fluxes and atmospheric profiles using nominal parameters. The inversion of synthetic data highlights the potential for retrieving information about ecosystems from atmospheric PBL profiles and tower based eddy covariance data.

\section{Data Sets \\ Study sites}

The CAB model was initialized with soil and vegetation parameters from two BOREAS field campaign sites. These sites, the northern study area old black spruce (NSA-OBS) site, and the southern study area old black spruce (SSA-OBS) site were located $\sim 500$ $\mathrm{km}$ apart, in Saskatchewan, Canada. For the SSA-OBS site, the study 1 period covered 120 days in the growing season, from 23 May (Day 143) to 19 September (Day 262) 1994. For the NSA-OBS, study 1 also covered 120 days during the growing season, making use of data from 31 May (day 151) till 27 September (day 270) 1994.

The eddy covariance (EC) tower at the SSA-OBS site $\left(53.99^{\circ} \mathrm{N}, 105.12^{\circ} \mathrm{W}\right.$ and $629 \mathrm{~m}$ altitude) was surrounded by a $10-11 \mathrm{~m}$ high canopy (Jarvis et al. 1997) dominated by black spruce (Picea mariana), with an average leaf area index (LAI) of 4.4 (Chen et al. 1997). The SSA-OBS site EC tower was equipped with a
LI-6262 infrared gas analyzer (LI-COR, Lincoln, Nebraska USA) and a Solent sonic anemometer (Gill Instruments Ltd, Lymington, UK) which were mounted on a $27 \mathrm{~m}$ tower, with an effective fetch of $\sim 1200 \mathrm{~m}$ in all directions (Jarvis et al. 1997, Jarvis and Moncrieff 2000, Newcomer et al. 2000).

The area around the NSA-OBS EC tower $\left(55.88^{\circ} \mathrm{N}\right.$, $98.48^{\circ} \mathrm{W}$ and $259 \mathrm{~m}$ altitude) was largely level, with mature black spruce dominant for several kilometers around the site (Goulden et al. 1997). The black spruce at this site had an average LAI of 5.6 (Chen et al. 1997). The NSA-OBS site EC tower used a LI-6262 (LI-COR, Lincoln, Nebraska USA) infrared gas analyzer and a three-axis Applied Technologies, Inc. (ATI) sonic anemometer (ATI, Longmont, Colorado, USA) which were mounted on a $31 \mathrm{~m}$ tall tower (Goulden et al. 1997, Newcomer et al. 2000, Wofsy et al. 2000). Gap filling of the meteorological data is described in Appendix A.

In addition to these data sets, other flux data from a number of other BOREAS eddy covariance sites were also used to explore the wider spatial variability in fluxes across the landscape (Sellers et al. 1997). From the SSA, the old jack pine (OJP), the young jack pine (YJP), the old aspen (OA) and the fen (Fen) EC flux data were used. From the NSA, the old jack pine (OJP), the young jack pine (YJP) and the fen (Fen) EC flux data were used.

Classification products from Landsat-5 TM imagery were used to estimate the fractional cover of each study area represented by each flux tower. The SSA classification used Landsat-5 TM image from 2 September 1994 and the NSA classification used an image from 21 June 1995 (Hall et al. 1997). Since the descriptions of the Landsat derived classifications did not exactly match the EC tower site species, classifications had to be assigned to the closest EC site species. Where two or more species could be attributed to a single Landsat classification, the area of the classification was equally divided amongst the species. By this calculation in the SSA, OBS covered $24 \%$, OJP 20\%, YJP 7\%, OA 29\%, and Fen 7\%; $13 \%$ remained unassigned (i.e., water, disturbed, fire blacken, or grass). In the NSA, OBS covered $18 \%$, OJP $11 \%$, YJP $9 \%$, and Fen 16\%; $46 \%$ remained unassigned (i.e., deciduous, water, disturbed, fire blacken, or grass). The SSA covers an area of approximately $144 \times 114 \mathrm{~km}$ and the NSA $129 \times 86 \mathrm{~km}$.

\section{$P B L$ data}

Atmospheric profile data came from the National Research Council of Canada's Twin Otter aircraft (Barr et al. 1997, MacPherson and Desjardins 2000, Newcomer et al. 2000). A LI-6262 (LI-COR, Lincoln, Nebraska USA) collected $\mathrm{CO}_{2}$ and $\mathrm{H}_{2} \mathrm{O}$ measurements from ground level to $2-2.5 \mathrm{~km}$. Data were recorded at 16 $\mathrm{Hz}$ and archived at $1 \mathrm{~Hz}$. Unfortunately the accuracy of the instrument is unknown. Additionally, the instrumentation on the Twin Otter was designed for highprecision measurements in level flight and in this study 
we were looking for differences between two vertical profiles. Despite this limitation, we assume any biases in the measurements will be correlated with height (i.e., pressure and temperature). However to mitigate the effect of any lags in the measurement error as the aircraft ascends and descends, only profile pairs flown in the same (ascending or descending) direction were compared.

Atmospheric profiles over both the SSA and the NSA are available for 42 days during the 1994 study period. Of these 42 flights, 30 were discarded as only a single boundary layer sounding was performed. A further two were discarded due to apparently erroneous jumps of 15-20 ppm in the above PBL concentration of $\mathrm{CO}_{2}$ within a two to three hour period. On one of these days the wind direction shifts 90 degrees between the profiles, suggesting a significant change in fetch; however this is not the case on the other day. Four more days flights were discarded due to transient low pressure systems. Finally, four profiles were discarded as the profile pairs contained both ascending and descending soundings through the PBL. The remaining two suitable days were day 205 (09:49 and 13:18, 24 July) SSA-OBS and day 159 (10:18 and 14:24, 8 June) NSA-OBS. Both days had benefited from a convective boundary layer. The mean wind speeds in the lower $1000 \mathrm{~m}$ were $6 \mathrm{~m} / \mathrm{s}$ for day 205 and $4 \mathrm{~m} / \mathrm{s}$ for day 159 . The separation between the profiles was 4 hours 23 minutes for day 205 and 4 hours 12 minutes for day 159. This gives approximate transit distances for the air between the profiles of $94 \mathrm{~km}$ for day 205 and $60 \mathrm{~km}$ for day 159, which are both shorter than the dimensions of the respective study areas.

\section{The CAB Model}

The coupled atmosphere-biosphere (CAB) model (Hill et al. 2008) is composed of two main components: a PBL model and a land surface exchange scheme. These models are the coupled atmospheric boundary layerplant-soil (CAPS) model which was based on the Oregon State University 1-dimensional planetary boundary layer (OSU1DPBL) model (Mahrt and Pan 1984, Troen and Mahrt 1986) and the soil-plant-atmosphere (SPA) model (Williams et al. 1996, 2001a, b). The SPA model was twinned with a respiration model to simulate net ecosystem exchange (NEE).

The CAPS model is a medium resolution boundary layer column model consisting of 68 atmospheric model layers extending beyond the PBL, from ground level to $10 \mathrm{~km}$. PBL dynamics are modeled as a combination of $\mathrm{K}$ theory and non-local mixing. In order to simplify the model, only the vertical diffusion (from turbulent mixing) and advection are considered when calculating the turbulent mixing within the PBL. Atmospheric dynamics in the PBL is modeled using a counter gradient term to modify the diffusivity. The counter gradient term is required to describe the non-local mixing arising from thermals and eddies (Priestley and Swinbank 1947, Deardorf 1966, Mailhot and Benoit 1982).
The SPA model has been adapted to run on the time step of the CAB model ( $4 \mathrm{~min}$ ) and is a process based ecosystem model (10 canopy layers and 20 soil layers) of canopy photosynthesis, evapotranspiration (ET), and soil heat and water exchanges. Within SPA, stomatal conductance is varied in order to maximize daily $\mathrm{C}$ gain within the constraints imposed by the plants' hydraulic limitations. That is, stomata are adjusted to maximize photosynthesis, while minimizing the risk of cavitations within the xylem through explicit modeling of plant water potential. SPA carries out radiative transfer calculations within the canopy, and determines the full surface energy balance (Williams et al. 2001 $a, b$ ). In this study, we have used the SPA model's ability to predict gross primary production (GPP), the total C fixed by plants in the ecosystem. However the $\mathrm{C}$ flux measured by EC systems is the net ecosystem exchange (NEE), the net accumulation of $\mathrm{C}$ in the ecosystem. The difference of the two is ecosystem respiration $(\mathrm{Re})$ : $\mathrm{NEE}=\mathrm{GPP}-\mathrm{Re}$.

Simulation of respiration was performed by a third model, a simple box model used in the data assimilation linked ecosystem C model (DALEC; Williams et al. 2005). DALEC simulates the allocation and storage of carbon using five carbon pools and nine turnover rates that determine the fluxes between the pools. DALEC takes the previous day's GPP and allocates a fixed fraction of it directly into autotrophic respiration. The remainder is the net primary production, and this is allocated into the foliage, wood, and fine root carbon pools. The wood carbon pool feeds into the soil organic matter (SOM) pool. Both the foliage and the fine root pools feed into the litter carbon pool. The litter pool then partly feeds into the SOM pool and is also partially respired heterotrophically. The SOM pool also contributes to the heterotrophic respiration. For a diagram of flows between these pools, see (Williams et al. 2005).

\section{Stage 1: CAB Model "Forward" Setup}

The CAB model was tested in two modes: mode 1, where the uncoupled biosphere model (SPA2, i.e., SPA+ DALEC) was run over an extended number of days, and mode 2, where the fully coupled, prognostic version of the $\mathrm{CAB}$ model was run on selected days. In both cases, the biosphere model was initialized with soil and vegetation parameters from two BOREAS field campaign sites.

Data from the BOREAS sites allowed for a nearly complete aboveground parameter set (for the SSA, see Hill et al. [2008] and for the NSA, see Table 1). The leaf capacitance and the water use efficiency parameter (t), which were heuristically fitted within ranges based on studies of ponderosa pine (Pinus ponderosa) and oakmaple (Quercus-Acer; Williams et al. 1996, 2001a). Tests showed the model to be largely insensitive to changes in leaf capacitance and $t$, as neither site experiences significant water stress during the growing season. Where available, turnover rate parameters and $\mathrm{C}$ pool sizes for the DALEC respiration sub-model were based 
TABLE 1. Northern study area, old black spruce site (NSA-OBS) model parameters; taken directly from the literature unless otherwise stated.

\begin{tabular}{|c|c|c|c|c|}
\hline Parameter/variable & Value/range & Units & Comments & Source \\
\hline \multicolumn{5}{|l|}{ Site information } \\
\hline Lattitude & 55.88 & ${ }^{\circ} \mathrm{N}$ & & $\begin{array}{l}\text { Wofsy et al. (2000), } \\
\text { Goulden et al. (1997), } \\
\text { Newcomer et al. (2000) }\end{array}$ \\
\hline Longitude & -98.48 & ${ }^{\circ} \mathrm{E}$ & & $\begin{array}{l}\text { Wofsy et al. (2000), } \\
\text { Goulden et al. (1997), } \\
\text { Newcomer et al. (2000) }\end{array}$ \\
\hline Altitude & 259 & $\mathrm{~m}$ & & Newcomer et al. (2000) \\
\hline \multicolumn{5}{|l|}{ Biosphere parameters } \\
\hline Leaf area index (LAI) & 5.3 & $\mathrm{~m}^{2} /\left(\mathrm{m}^{2}\right.$ ground area $)$ & & Chen et al. (1997) \\
\hline $\begin{array}{l}\text { Total foliar nitrogen } \\
\text { (FN) }\end{array}$ & 9.3 & $\mathrm{~g} /\left(\mathrm{m}^{2}\right.$ leaf area $)$ & & Rayment et al. (2002) \\
\hline $\begin{array}{l}\text { Maximum } \\
\text { carboxylation } \\
\text { capacity, } \mathrm{Vc}_{\max }\end{array}$ & 11 & $\mu \mathrm{mol} \mathrm{CO} 2 \cdot \mathrm{m}^{-2} \cdot \mathrm{s}^{-1}$ & calibrated on DoY 160 & Rayment et al. (2002) \\
\hline $\begin{array}{l}\text { Maximal electron } \\
\text { transport rate, } J_{\max }\end{array}$ & 31.3 & $\mu \mathrm{mol} \mathrm{e}{ }^{-} \cdot \mathrm{m}^{-2} \cdot \mathrm{s}^{-1}$ & calibrated on DoY 160 & Rayment et al. (2002) \\
\hline $\begin{array}{l}\text { Plant hydraulic } \\
\text { conductance }\end{array}$ & 6 & $\mathrm{mmol} \cdot \mathrm{m}^{-1} \cdot \mathrm{s}^{-1} \cdot \mathrm{MPa}^{-1}$ & $\begin{array}{l}\text { calibrated using the } \\
\text { hydraulic conductance } \\
\text { per leaf area }(\mathrm{KL})\end{array}$ & Ewers et al. (2005) \\
\hline $\begin{array}{l}\text { Minimum leaf water } \\
\text { potential }\end{array}$ & -1.5 & Mpa & & Ewers et al. (2005) \\
\hline Leaf capacitance & 2000 & $\mathrm{mmol} \cdot \mathrm{m}^{-2} \cdot \mathrm{s}^{-1}$ & & \\
\hline Water use efficiency, 1 & 1.0085 & & & \\
\hline Root resistance & 150 & $\mathrm{Mpa}^{-\mathrm{s}^{-1}} \cdot \mathrm{m}^{2} \cdot \mathrm{mmol}^{-1}$ & calibrated using KL & Ewers et al. (2005) \\
\hline Tower height & 29 & $\mathrm{~m}$ & & Goulden et al. (1997) \\
\hline PAR leaf reflectance & 0.11 & & tuned & Betts and Ball (1997) \\
\hline PAR leaf transmission & 0.16 & & tuned & Betts and Ball (1997) \\
\hline PAR soil reflectance & 0.08 & & & Miller et al. (1997) \\
\hline NIR leaf reflectance & 0.43 & & tuned & Betts and Ball (1997) \\
\hline NIR leaf transmission & 0.26 & & tuned & Betts and Ball (1997) \\
\hline NIR soil reflectance & 0.37 & & & Miller et al. (1997) \\
\hline \multicolumn{5}{|l|}{ Belowground distributions } \\
\hline Organic fraction & $0.0 / 0.5$ & & & $\begin{array}{l}\text { Anderson (2000), Saxton } \\
\text { et al. (1986) }\end{array}$ \\
\hline Mineral fraction & $0.0 / 0.5$ & & & $\begin{array}{l}\text { Anderson (2000), Saxton } \\
\text { et al. (1986) }\end{array}$ \\
\hline Water/ice fraction & $0.02 / 0.75$ & & & $\begin{array}{l}\text { Cuenca et al. (1997), } \\
\text { Cuenca (2000) }\end{array}$ \\
\hline Soil temperature & $-0.2 / 29.4$ & ${ }^{\circ} \mathrm{C}$ & & $\begin{array}{l}\text { Wofsy et al. (2000), } \\
\text { Goulden et al. (1997), } \\
\text { Newcomer et al. (2000) }\end{array}$ \\
\hline Fine root distribution & $0.0 / 0.3$ & $\mathrm{~m}$ & & Steele et al. (1997) \\
\hline Fine root biomass & 591 & $\mathrm{~g} / \mathrm{m}^{2}$ & & Steele et al. (1997) \\
\hline Sand fraction & $0.65 / 0.90$ & & & Anderson (2000) \\
\hline Clay fraction & $0.10 / 0.15$ & & & Anderson (2000) \\
\hline Silt fraction & $0.00 / 0.26$ & & & Anderson (2000) \\
\hline \multicolumn{5}{|l|}{ Atmospheric parameters } \\
\hline $\begin{array}{l}\text { Air temperature (above } \\
\text { canopy) }\end{array}$ & $-10.8 / 29.4$ & ${ }^{\circ} \mathrm{C}$ & & $\begin{array}{l}\text { Wofsy et al. (2000), } \\
\text { Goulden et al. (1997), } \\
\text { Newcomer et al. (2000) }\end{array}$ \\
\hline VPD (above canopy) & $0.0 / 3.11$ & $\mathrm{kPa}$ & & $\begin{array}{l}\text { Wofsy et al. (2000), } \\
\text { Goulden et al. (1997), } \\
\text { Newcomer et al. (2000) }\end{array}$ \\
\hline PAR (above canopy) & $0 / 2277$ & $\mu \mathrm{mol} \cdot \mathrm{m}^{-2} \cdot \mathrm{s}^{-1}$ & & $\begin{array}{l}\text { Wofsy et al. (2000), } \\
\text { Goulden et al. (1997), } \\
\text { Newcomer et al. (2000) }\end{array}$ \\
\hline $\begin{array}{l}\text { Wind speed (above } \\
\text { canopy) }\end{array}$ & $0.0 / 9.0$ & $\mathrm{~m} / \mathrm{s}$ & & $\begin{array}{l}\text { Wofsy et al. (2000), } \\
\text { Goulden et al. (1997), } \\
\text { Newcomer et al. (2000) }\end{array}$ \\
\hline Precipitation & $0 / 33$ & $\mathrm{~mm} / \mathrm{d}$ & & $\begin{array}{l}\text { Wofsy et al. (2000), } \\
\text { Goulden et al. (1997), } \\
\text { Newcomer et al. (2000) }\end{array}$ \\
\hline Roughness length, $Z_{0}$ & 1 & $\mathrm{~m}$ & & $\begin{array}{l}\text { Holtslag and Vanulden } \\
\text { (1983) }\end{array}$ \\
\hline Albedo & 0.093 & & & Betts and Ball (1997) \\
\hline
\end{tabular}


TABle 1. Continued.

\begin{tabular}{|c|c|c|c|c|}
\hline Parameter/variable & Value/range & Units & Comments & Source \\
\hline Fractional cloud cover & $0 / 0.7$ & & & $\begin{array}{l}\text { Wofsy et al. (2000), } \\
\text { Goulden et al. (1997), } \\
\text { Newcomer et al. (2000) }\end{array}$ \\
\hline $\begin{array}{l}\text { Horizontal wind } \\
\text { speed, } u\end{array}$ & $\begin{array}{c}0.0 / 5.8 \\
(\text { DoY } 167)\end{array}$ & $\mathrm{m} / \mathrm{s}$ & & $\begin{array}{l}\text { Barr et al. (1997), } \\
\text { MacPherson et al. (2000), } \\
\text { Newcomer et al. (2000) }\end{array}$ \\
\hline $\begin{array}{l}\text { Horizontal wind } \\
\text { speed, } v\end{array}$ & $\begin{array}{c}0.0 / 8.8 \\
(\text { DoY } 250)\end{array}$ & $\mathrm{m} / \mathrm{s}$ & & $\begin{array}{l}\text { Barr et al. (1997), } \\
\text { MacPherson et al. (2000), } \\
\text { Newcomer et al. (2000) }\end{array}$ \\
\hline $\begin{array}{l}\text { Potential temperature }(0 \\
-3000 \mathrm{~m} \text { elevation })\end{array}$ & $\begin{array}{l}282.1,294.1 \\
\text { (DoY 167) }\end{array}$ & $\mathrm{K}$ & & $\begin{array}{l}\text { Barr et al. (1997), } \\
\text { MacPherson et al. (2000), } \\
\text { Newcomer et al. (2000) }\end{array}$ \\
\hline $\begin{array}{l}\text { Potential temperature }(0 \\
-3000 \mathrm{~m} \text { elevation })\end{array}$ & $\begin{array}{l}286.7,302.1 \\
(\text { DoY 250) }\end{array}$ & $\mathrm{K}$ & & $\begin{array}{l}\text { Barr et al. (1997), } \\
\text { MacPherson et al. (2000), } \\
\text { Newcomer et al. (2000) }\end{array}$ \\
\hline $\begin{array}{l}\text { Mixing ratio }(0-3000 \mathrm{~m} \\
\text { elevation) }\end{array}$ & $\begin{array}{c}1.0,5.4 \\
(\text { DoY } 167)\end{array}$ & $\mathrm{g} / \mathrm{kg}$ & & $\begin{array}{l}\text { Barr et al. (1997), } \\
\text { MacPherson et al. (2000), } \\
\text { Newcomer et al. (2000) }\end{array}$ \\
\hline $\begin{array}{l}\text { Mixing ratio }(0-3000 \mathrm{~m} \\
\text { elevation) }\end{array}$ & $\begin{array}{c}4.7,6.9 \\
(\text { DoY } 250)\end{array}$ & $\mathrm{g} / \mathrm{kg}$ & & $\begin{array}{l}\text { Barr et al. (1997), } \\
\text { MacPherson et al. (2000), } \\
\text { Newcomer et al. (2000) }\end{array}$ \\
\hline \multicolumn{5}{|l|}{ Respiration model parameters } \\
\hline $\begin{array}{l}\text { Litter decomposition } \\
\text { rate constant, } t 1\end{array}$ & 0.0000044 & $\mathrm{~g} \mathrm{C} \cdot \mathrm{m}^{-2} \cdot \mathrm{d}^{-1}$ & fitted within range & Williams et al. (2005) \\
\hline $\begin{array}{l}\text { Autotrophic respiration } \\
\text { (Frac. GPP), } t 2\end{array}$ & 0.5 & & fitted within range & Williams et al. (2005) \\
\hline $\begin{array}{l}\text { Frac. NPP allocated to } \\
\text { foliage, } t 3\end{array}$ & 0.08 & & $\begin{array}{l}\text { total above- }+ \\
\quad \text { belowground NPP }\end{array}$ & $\begin{array}{l}\text { Jarvis et al. (1997), Gower } \\
\text { et al. (1997) }\end{array}$ \\
\hline $\begin{array}{l}\text { Frac. NPP allocated to } \\
\text { fine roots, } t 4\end{array}$ & 0.47 & & $\begin{array}{l}\text { total above- }+ \\
\text { belowground NPP }\end{array}$ & $\begin{array}{l}\text { Jarvis et al. (1997), Gower } \\
\text { et al. (1997) }\end{array}$ \\
\hline Turnover rate foliage, $t 5$ & 0.0005 & $\mathrm{~g} \mathrm{C} \cdot \mathrm{m}^{-2} \cdot \mathrm{d}^{-1}$ & fitted within range & Williams et al. (2005) \\
\hline $\begin{array}{l}\text { Turnover rate woody } \\
\text { matter, } t 6\end{array}$ & 0.0001 & $\mathrm{~g} \mathrm{C} \cdot \mathrm{m}^{-2} \cdot \mathrm{d}^{-1}$ & fitted within range & Williams et al. (2005) \\
\hline $\begin{array}{l}\text { Turnover rate fine } \\
\text { roots, } t 7\end{array}$ & 0.00007 & $\mathrm{~g} \mathrm{C} \cdot \mathrm{m}^{-2} \cdot \mathrm{d}^{-1}$ & & Steele et al. (1997) \\
\hline $\begin{array}{l}\text { Mineralization rate of } \\
\text { fresh litter, } t 8\end{array}$ & 0.0015 & $\mathrm{~g} \mathrm{C} \cdot \mathrm{m}^{-2} \cdot \mathrm{d}^{-1}$ & fitted within range & Williams et al. (2005) \\
\hline $\begin{array}{l}\text { Mineralization rate of } \\
\text { SOM and woody } \\
\text { debris, } t 9\end{array}$ & 0.000023 & $\mathrm{~g} \mathrm{C} \cdot \mathrm{m}^{-2} \cdot \mathrm{d}^{-1}$ & fitted within range & Williams et al. (2005) \\
\hline Foliage, $\mathrm{Cf}$ & 556 & $\mathrm{~g} \mathrm{C} / \mathrm{m}^{2}$ & $\begin{array}{l}\text { fresh }+ \text { old }+ \\
\text { understory }\end{array}$ & Gower et al. (1997) \\
\hline $\begin{array}{l}\text { Wood (stems }+ \text { coarse } \\
\text { roots) }, \mathrm{CW}\end{array}$ & 5985 & $\mathrm{~g} \mathrm{C} / \mathrm{m}^{2}$ & $\begin{array}{l}\text { stem/trunk + live coarse } \\
\text { root mass }\end{array}$ & $\begin{array}{l}\text { Steele et al. (1997), Gower } \\
\quad \text { et al. (1997) }\end{array}$ \\
\hline Fine roots, $\mathrm{Cr}$ & 591 & $\mathrm{~g} \mathrm{C} / \mathrm{m}^{2}$ & & Steele et al. (1997) \\
\hline $\begin{array}{l}\text { Fresh foliar and fine } \\
\quad \text { root litter, Clit }\end{array}$ & 363.6 & $\mathrm{~g} \mathrm{C} / \mathrm{m}^{2}$ & dead fine roots + litter & $\begin{array}{l}\text { Gower et al. (1997), Nakane } \\
\text { et al. (1997) }\end{array}$ \\
\hline $\begin{array}{l}\text { SOM + woody debris, } \\
\text { Csom }\end{array}$ & 20616 & $\mathrm{~g} \mathrm{C} / \mathrm{m}^{2}$ & & $\begin{array}{l}\text { Gower et al. (1997), Savage } \\
\text { et al. (1997) }\end{array}$ \\
\hline Tresponse & 0.79 & & & Williams et al. (2005) \\
\hline
\end{tabular}

Notes: When two values are given, they are the minimum and maximum values. Abbreviations are: PAR, photosynthetically available radiation; NIR, near infrared; VPD, vapor pressure deficit; DoY, day of year; GPP, gross primary productivity; NPP, net primary productivity; Frac., fraction of; SOM, soil organic matter; Tresponse, temperature-sensitive rate parameter.

on literature values (Table 1). Unknown turnover rates were fitted within a range of values (Williams et al. 2005), and tuned to maintain steady C pool sizes over the study periods. Daily autotrophic respiration from DALEC was disaggregated from a daily to an hourly flux using a sinusoidal function.

Mode 1 was initialized at midnight at the start of the 120-day study periods with measured soil temperature and moisture profiles. In this mode, the model was driven for 120 days using meteorological surface data from each of the flux tower site.
Mode 2, the prognostic CAB model (Fig. 1), was initialized at midnight local time on two test days and run for a simulation time of 24 hours. In this mode, $\mathrm{CAB}$ generates its own meteorology using the coupled atmospheric boundary layer-plant-soil (CAPS) routines. The exceptions are the cloud fraction and precipitation which are both prescribed. Precipitation was obtained from measurements at the OBS EC sites, and a fractional cloud cover was estimated from the radiation data at the sites. CAPS predictions of air temperatures, carbon dioxide $\left(\mathrm{CO}_{2}\right)$ concentrations, 
FIG. 1 The fully coupled atmosphere-biosphere (CAB) model includes the soil-plantatmosphere (SPA) model and the respiration model of the data assimilation linked ecosystem C (DALEC) model. Other abbreviations are: CAPS, coupled atmospheric boundary layer plant-soil model; GPP, gross primary production; PAR, photosynthetically active radiation; VPD, vapor pressure deficit; NEE, net ecosystem exchange; ET, evapotranspiration; LE, latent energy.

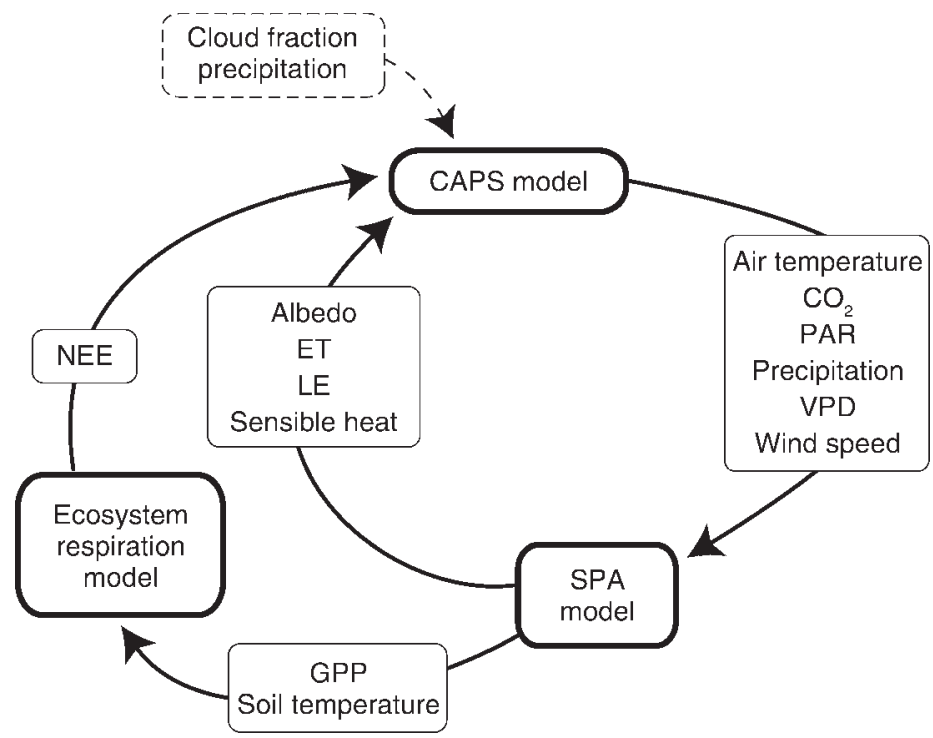

photosynthetically active radiation (PAR), precipitation (prescribed), vapor pressure deficit (VPD), and wind speeds for the first model layer are passed to the SPA model. Driven by these fields, SPA then calculates the vegetation's response providing the albedo, evapotranspiration (ET), latent energy (LE), and sensible heat predictions required to drive the CAPS model. To calculate NEE, SPA passes the respiration model estimates of GPP and soil temperatures. The dynamics of the CAB model necessitate starting at midnight. The soil states are initialized at midnight from observations and the remaining states, including the soil carbon pool sizes, are extracted from the 120-day model runs. The atmospheric component of the CAB model cannot be initialized at midnight from measurements as this information is unavailable. Instead the first profile of the each day was used as a basis for the midnight atmospheric profile, this profile was then heuristically amended such that the model predictions achieved a qualitatively good fit with the first profile of the day.

\section{Stage 2: The CAB Inversion}

The goal of the inversion was to determine the values of ecological parameters in the CAB model from PBL observations of $\mathrm{CO}_{2}$, water mixing ratio and temperature and from eddy covariance measurements of $\mathrm{C}$ and LE fluxes. The prognostic CAB model is used in a Monte Carlo inversion method, described in practical terms in Appendix B (Mosegaard and Tarantola 1995, Knorr and Kattge 2005). The Monte Carlo inversion method is just one form of analysis which is based on Bayes's theorem, circa 1763 (Bayes 1763). Bayes' theory allows for a priori knowledge about a system to be revised using new observations. The inversion scheme was run using synthetic data from a forward run of the CAB model (day 205, 24 July 1994 at the SSA-OBS) with appropriate noise added. The following sections will describe the inversion scheme setup and the generation of the synthetic data.

\section{Choice of parameters}

To reduce parameter space for a simplified analysis, the model response to six parameters was explored; four from SPA (leaf area index, foliar nitrogen per leaf area, plant hydraulic conductance, and albedo), one from CAPS (roughness length) and one pseudo-parameter from DALEC (a respiration "gain" factor). These parameters were chosen as they represent strong and distinct controls on the hydraulic and photosynthetic/ radiative capacities of the vegetation, as well as the mechanical interaction with the atmosphere. In the DALEC respiration model there is no overall rate controlling the respiration, therefore a overall "gain" factor was applied. The prior values for these parameters were taken from the literature values, and the gain on respiration was assumed to be 1 . In the Bayesian analysis parameters are converted into log normalized parameters, where the prior value has a log normal value of 1 (see Appendix B).

\section{Generating the synthetic data}

Rather than inverting the BOREAS aircraft and EC measurements directly, twin (synthetic) data sets were used to simplify the interpretation of the inversion results. The synthetic data were generated using the prognostic coupled CAB model run from day 205. From this run synthetic PBL profiles of temperature, water mixing ratio and $\mathrm{CO}_{2}$ were saved at the same time of day as the second of the actual observations on day 205, i.e., 13:18. NEE and LE fluxes were saved as 30-minute values.

Uncertainties for EC measurements and aircraft profiles are hard to estimate. Both the systematic and random errors associated with $\mathrm{EC}$ data have been 
extensively studied (Goulden et al. 1996, Hollinger and Richardson 2005). Loescher et al. (2006) conclude that the treatments of errors are inherently site specific, and so assumptions for the errors in our twin experiment have to be made. In the twin experiment, "standard" EC observation uncertainties were assumed to be Gaussian with standard deviations of $20 \%$ for LE, $20 \%$ for daytime NEE, and $50 \%$ for nighttime NEE, as used in other experiments (Knorr and Kattge 2005). This is a simplification of the uncertainties necessary to work within the assumptions of the Bayesian inversion. However the use of a larger nocturnal uncertainty for NEE was supported by a random error analysis (Hollinger and Richardson 2005). In this analysis we found nocturnal periods to have larger NEE uncertainties despite the smaller overall nocturnal fluxes. Whilst measurement uncertainties for the aircraft measurements were available and comparatively small, total uncertainties including atmospheric variability were harder to determine. The profile measurement error used in this study were expressed as standard deviations of $0.5 \mathrm{~K}$ for air temperature, $0.25 \mathrm{~g} / \mathrm{kg}$ for water mixing ratio, and $0.75 \mathrm{ppm}$ for $\mathrm{CO}_{2}$ concentration. These standard deviations encompassed the measurement error, and where possible were within the ranges quoted in literature (Raupach et al. 2005). These uncertainties were used in the accept/reject step of the Bayesian analysis framework, see Appendix B.

\section{Individual inversion setup}

First the inversion was run with flat a priori (i.e., no prior information) and twin data without any uncertainty being added. The permissible range of log-normal parameter values was bounded between -2 and 4 . These bounds gave the inversion a broad range of permissible model parameter values (from $1 / 20$ th to 20 times the a priori model parameter value). This set of inversions consisted of three different setups, which used different combinations of observations to constrain the inversion; (1) using NEE and LE eddy covariance observations, (2) using PBL measurements (from $200 \mathrm{~m}$ to $800 \mathrm{~m}$ ), and (3) using both EC and PBL measurements. Using the Gelman criteria the length of the analysis was set to 300000 accepted steps (Gelman 1995).

Second, an inversion was run to discover the likely impacts of biased a priori values. The same synthetic data were inverted with random Gaussian noise added to the measurements as per the previous section. Initially the a priori were set at best guess values (i.e., the values from the forward runs). No actual uncertainties estimates were available for the a priori parameters, and so in accordance with previous studies the lognormal standard deviation was set at 0.25 (Knorr and Kattge 2005). That is, $\log$ normal a priori, $P_{i}=1$, with a standard deviation of 0.25 . Bias was introduced by setting the a priori higher or lower by one standard deviation, i.e., $P_{i}=1.25$ or $P_{i}=0.75$. For each of these three sets of a priori, the inversion was performed with just eddy covariance flux data, just aircraft profile data and both flux and profile data. This gave a total of nine inversion runs. The Gelman criteria (Gelman 1995) indicated that the length of the analysis could be reduced to 20000 accepted steps as the use of a priori information significantly reduces the region of parameter space to be explored.

\section{Stage 1: Forward Model Results}

The mode 1 forward runs of the $\mathrm{CAB}$ model were compared first to 120 days of daily aggregated EC data at both the NSA-OBS and SSA-OBS sites. For the 120day (daily aggregate), simulated LE from the biosphere model compared favorably to data with $R^{2}$ value for LE flux estimates of 0.70 for the SSA-OBS and 0.58 for the NSA-OBS site. The root mean square errors (RMSE) for $\mathrm{LE}$ were $1.19 \mathrm{MJ} \cdot \mathrm{m}^{-2} \cdot \mathrm{d}^{-1}$ (SSA-OBS) and 1.37 $\mathrm{MJ} \cdot \mathrm{m}^{-2} \cdot \mathrm{d}^{-1}$ (NSA-OBS). For 30-minute fluxes over the 120 days, LE flux $R^{2}$ estimates were 0.72 and 0.59 , and RMSEs were $40 \mathrm{~W} / \mathrm{m}^{2}$ for the SSA-OBS site and $42 \mathrm{~W} /$ $\mathrm{m}^{2}$ for the NSA-OBS site.

NEE estimates on a daily time-step had a lower correlation with measurements than LE estimates, with the SSA-OBS site having higher model-observation agreement than the NSA-OBS. NEE $R^{2}$ values were 0.37 and 0.25 , and RMSE values were $1.08 \mathrm{~g} \mathrm{C} \cdot \mathrm{m}^{-2} \cdot \mathrm{d}^{-1}$ for the SSA-OBS and $1.18 \mathrm{~g} \mathrm{C} \cdot \mathrm{m}^{-2} \cdot \mathrm{d}^{-1}$ for the NSA-OBS site. Correlations for the study period on a 30-minute time step were higher (Fig. 2), with NEE $R^{2}$ values of 0.59 (SSA-OBS) and 0.62 (NSA-OBS) and RMSE values of $4.0 \mu \mathrm{mol} \cdot \mathrm{m}^{-2} \cdot \mathrm{s}^{-1} \quad$ (SSA-OBS) and 3.4 $\mu \mathrm{mol} \cdot \mathrm{m}^{-2} \cdot \mathrm{s}^{-1}$ (NSA-OBS). The nocturnal respiration was poorly represented on several days, with the model over estimating the flux.

The responses of the OBS sites are qualitatively similar to that of the weighted flux of all the towers in the SSA and NSA (Fig. 2). This weighted flux was calculated using all the flux towers in each study area. The fluxes were weighted according to the fractional area of the SSA or NSA assigned to each flux tower species.

Comparing the CAB model (run in mode 2) output to the aircraft soundings revealed good model-measurement agreement on both days (Fig. 3). As expected, all modeled profiles show significantly less variation with height than observed in the measurements. The modeled profiles captured the important features of the boundary layer (i.e., the boundary layer temperature inversion and mixed layer concentrations). Evolution of modeled potential temperature mirrors that of the observations, maintaining a well-mixed region topped by a stable region. Observations from day 205 (SSA-OBS) revealed a moister mixed layer $(\sim 5 \mathrm{~g} / \mathrm{kg})$ compared to day 159 (NSA-OBS, $\sim 3 \mathrm{~g} / \mathrm{kg}$ ). Both days' simulated water mixing ratios showed similar increases in total atmospheric vapor content to the measurements.

Comparisons between the model and measurement PBL $\mathrm{CO}_{2}$ budgets were performed for day 159 between 

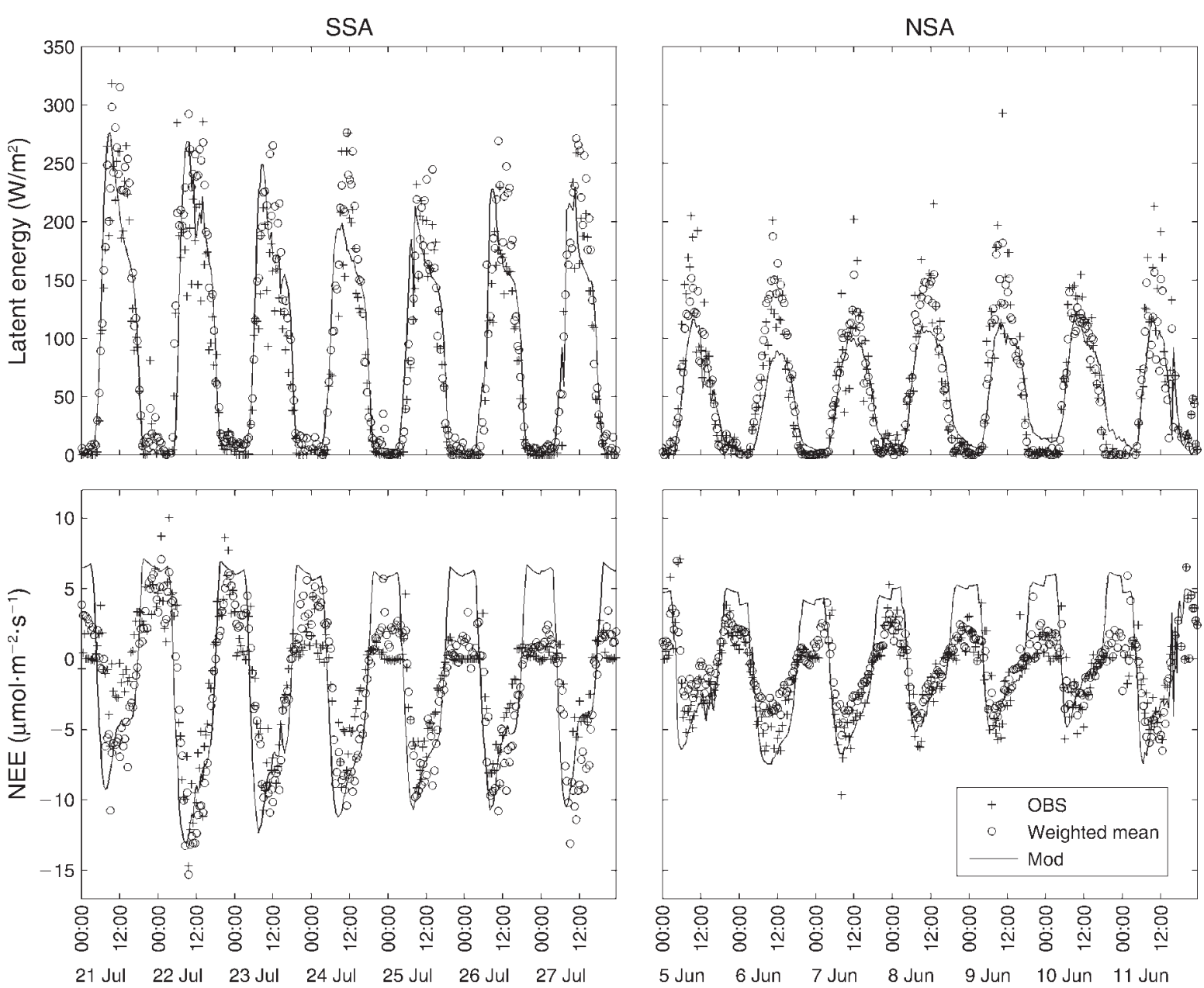

FIG. 2. The response of the off-line biosphere model (Mod) compared to the southern study area (SSA) and northern study area (NSA) eddy flux tower measurements during the 1994 study period. For each site, a seven-day period is selected from the $120-$ day model run. These periods are centered on the days with suitable planetary boundary layer (PBL) profiles. At both sites the old black spruce (OBS) site flux data are shown, as is the weighted mean flux from all available flux towers in each study area. These weights are estimated from fractional land cover in the SSA and NSA. In the SSA the contributions from the Fen, old aspen (OA), OBS, old jack pine (OJP), and young jack pine (YJP) and sites were weighted according to a land cover classification derived from Landsat imagery. In the NSA the weighted average was calculated from the Fen, OBS, OJP, and YJP sites.

10:18 and 14:24, and for day 205 between 09:49 and 13:18 pm. To determine the vertical extent to include in the budget, a cumulative sum of the molar content of $\mathrm{CO}_{2}$ was calculated. The height chosen contained the maximum possible molar content common to both profiles. That is, PBL profiles of equal molar volumes were compared. Thus due to pressure and temperature changes the height of the morning and afternoon profiles used differed slightly. The resulting region of the profiles used for estimating the NEE estimate were approximately the same as the PBL aircraft sounding height ( $\sim 1550 \mathrm{~m}$ for day 159 and $\sim 1400 \mathrm{~m}$ for day 205$)$ and extended above the PBL. Calculated over the 4 hour 23 minute period on day 205 , the observed flux was $-4.8 \mathrm{~g}$ $\mathrm{C} \cdot \mathrm{m}^{-2} \cdot \mathrm{d}^{-1}$ and the modeled flux was $-4.8 \mathrm{~g} \mathrm{C} \cdot \mathrm{m}^{-2} \cdot \mathrm{d}^{-1}$. Calculated over the 4 hour 12 minute period on day 159 , the observed flux was $-8.3 \mathrm{~g} \mathrm{C} \cdot \mathrm{m}^{-2} \cdot \mathrm{d}^{-1}$ and the modeled flux was $-5.8 \mathrm{~g} \mathrm{C} \cdot \mathrm{m}^{-2} \cdot \mathrm{d}^{-1}$.

\section{Stage 2: Inversion Results}

The first inversion, using flat a priori had very variable constraints on the different model parameters (Fig. 4). The results of the inversion show that LAI and respiration were well constrained. Albedo, roughness length, foliar nitrogen, and the plant hydraulic conductance had strong one-sided constraints. Of these, albedo, foliar nitrogen, and hydraulic conductance were strongly restricted by the prescribed log-normal parameter bounds ( -2 to 4$)$. The aircraft data on its own provided the least constraint of the three tests. EC measurements provided a better constraint for the parameters, and, as expected, using both aircraft and 

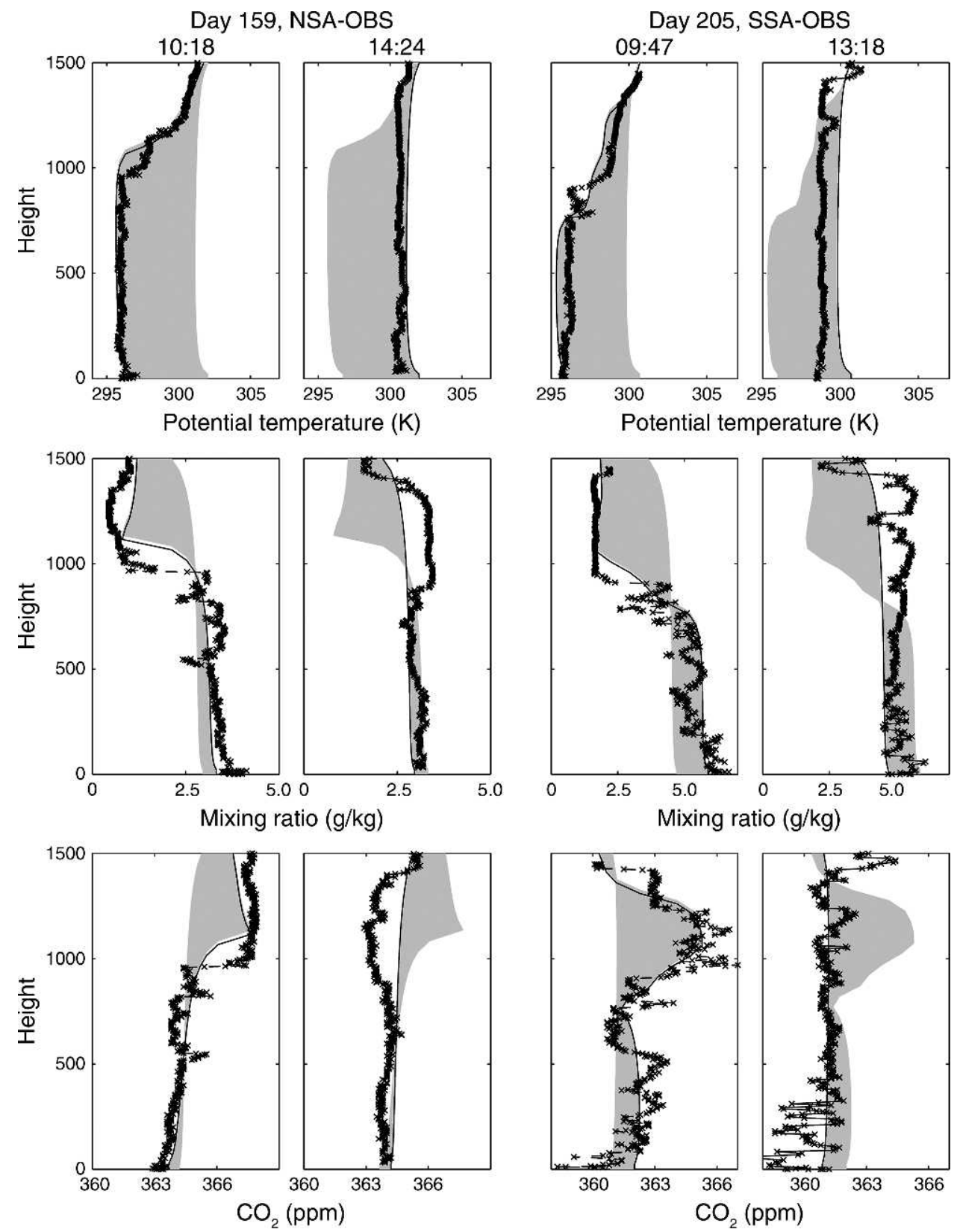

FIG. 3. Modeled and measured boundary layer profiles of potential temperature, mixing ratio, and $\mathrm{CO}_{2}$ concentration for day 159 (NSA-OBS) and for day 205 (SSA-OBS), 1994. Profiles are from aircraft flights through the boundary layer; local time is shown. Measurements are shown as diagonal crosses, and modeled data by solid lines. The gray shaded area shows the full extent covered by the modeled profiles (for the time period between the two PBL soundings) and is shown to provide a visual guide for the diurnal progression of the measured and modeled profiles.

EC data provided the greatest constraint on the parameters. The combined approach yielded standard deviations that were on average $84 \%$ of the EC-only inversion and $74 \%$ of the aircraft-only inversion.

The use of non-flat a priori altered the parameter retrieval, with tightened posteriori distributions (Fig. 5) on LAI and respiration, and to a lesser extent conductance and albedo. The posteriori distributions for foliar nitrogen and roughness were essentially the same as the a priori, wither the a priori were biased or not. With unbiased a priori the median of all posteriori distributions was within one standard deviation of the synthetic truth. The exception being albedo inverted from eddy flux data alone, which was just greater than one standard deviation. Using biased a priori reduced the percentage of median posteriori within one standard deviation to $58 \%$ for just fluxes, $58 \%$ for just profiles and $67 \%$ for both. The performance of inverting just fluxes 


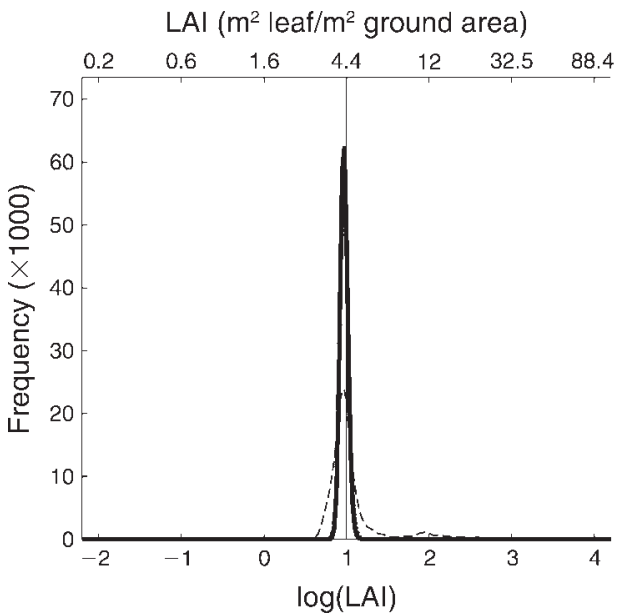

Foliar nitrogen ( $\mathrm{g} \mathrm{N} / \mathrm{m}^{2}$ leaf)
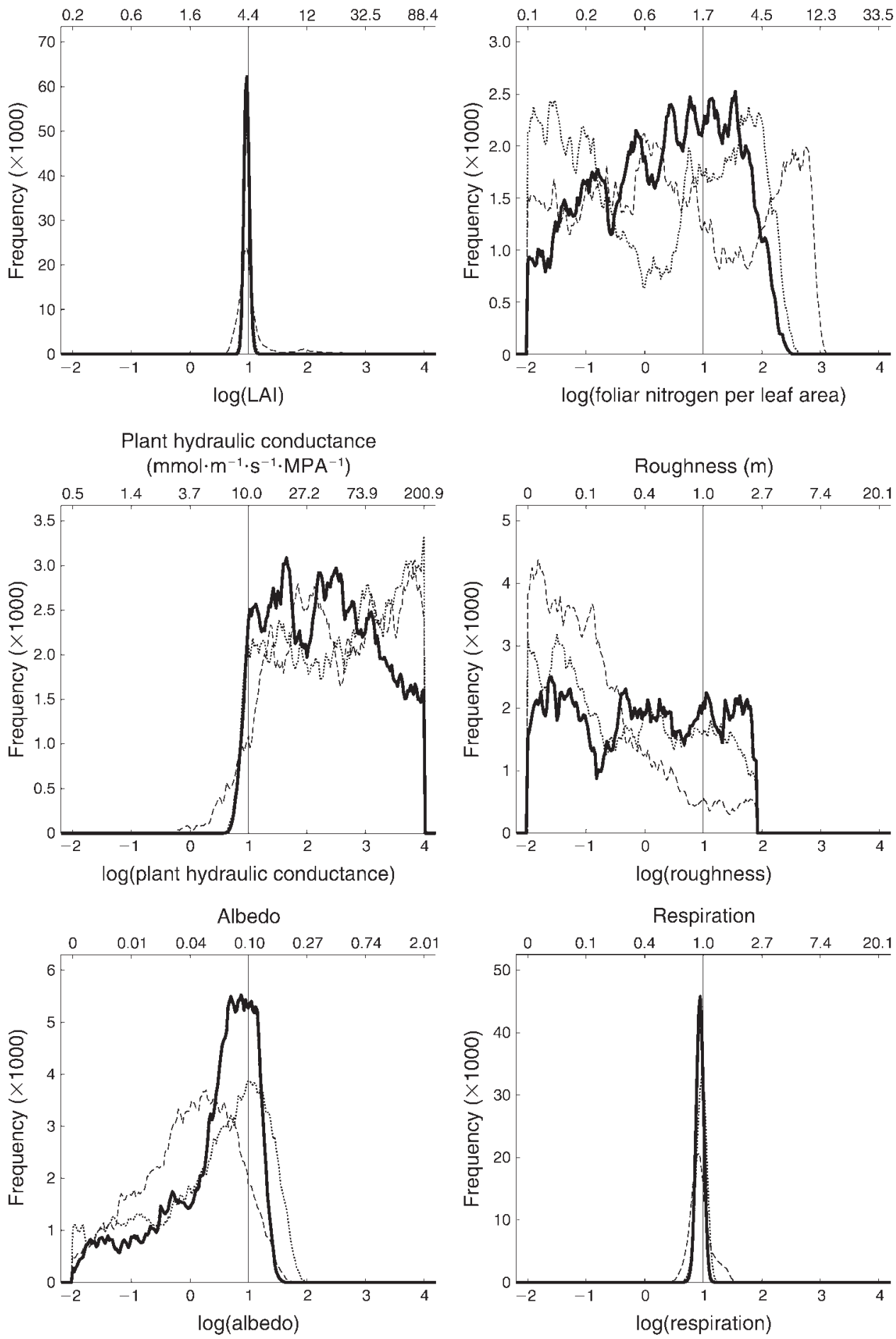

FIG. 4. The constraints placed on the posteriori distributions of six parameters by the model and the observations. Flat a priori constraints are used for this analysis, and the CAB model was constrained by flux data and aircraft observations. Solid lines are aircraft soundings + flux data, dotted lines are flux data only, and dashed lines are aircraft soundings. Lognormal parameter values are shown on the bottom of each panel, with the actual value on top. LAI stands for leaf area index. Note that the $y$-axis scale numbers should be multiplied by 1000 to obtain the true frequencies. 

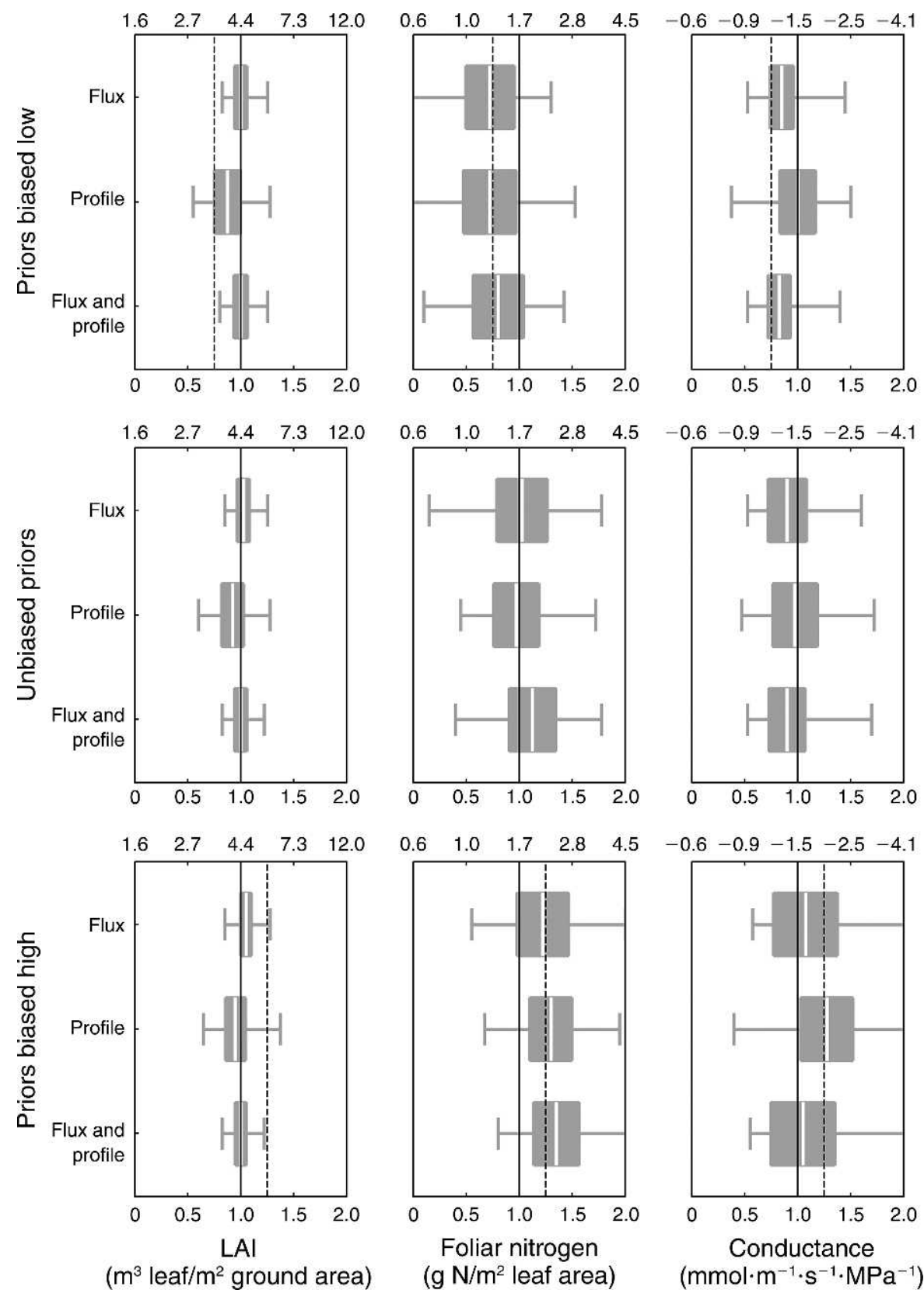

FIG. 5. This figure shows the modification to the posteriori distributions that can be expected from biased a priori when inverting both eddy covariance (EC) and flux (PBL) measurements. The distributions are described by the median (white line), standard deviation (gray box) and the full range (whiskers). The true synthetic parameters are indicated with a black line, and the a priori with a dotted line. The normal logs of the parameter values are shown in the bottom scale of each panel, with the actual values shown on top.

and just profiles was very similar. However, fluxes appeared to be a better constraint on LAI and the profiles a better constraint on albedo.

\section{Discussion}

Modeling of diurnal variation in ecosystem C fluxes is a mature area of research and so it is unsurprising that the biosphere component of the forward model (stage 1) compares favorably to the observations of fluxes from EC data at both sites (Fig. 2). The notable exception to this is the nocturnal respiration flux for several days during the periods shown, where the model does not replicate the reduction of nocturnal NEE fluxes to $0-2$ $\mu \mathrm{mol} \cdot \mathrm{m}^{-2} \cdot \mathrm{s}^{-1}$. A corresponding difference on the daytime fluxes is not observed. Indeed the model, measurement differences are only observed on certain days. This 

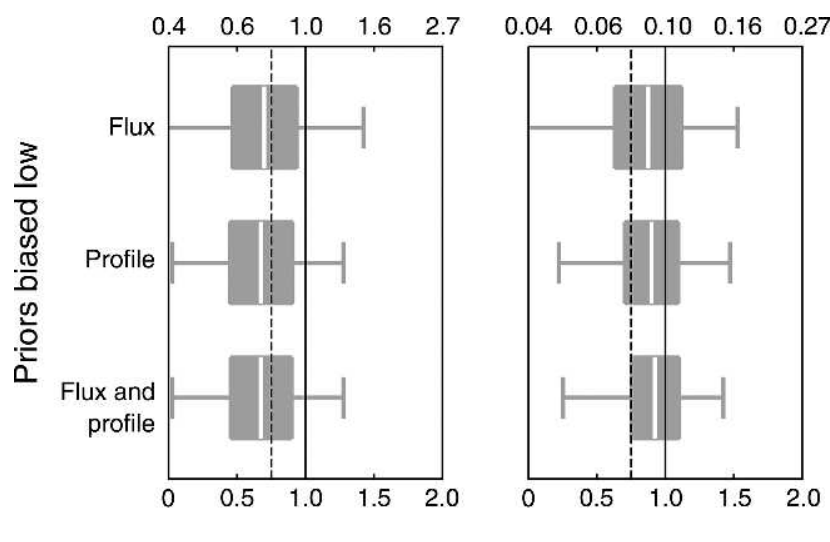

$\begin{array}{lllll}0.4 & 0.6 & 1.0 & 1.6 & 2.7\end{array}$

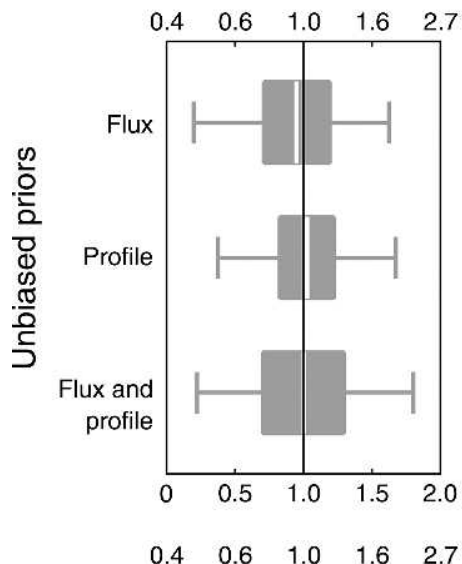

$\begin{array}{lllll}0.04 & 0.06 & 0.10 & 0.16 & 0.27\end{array}$
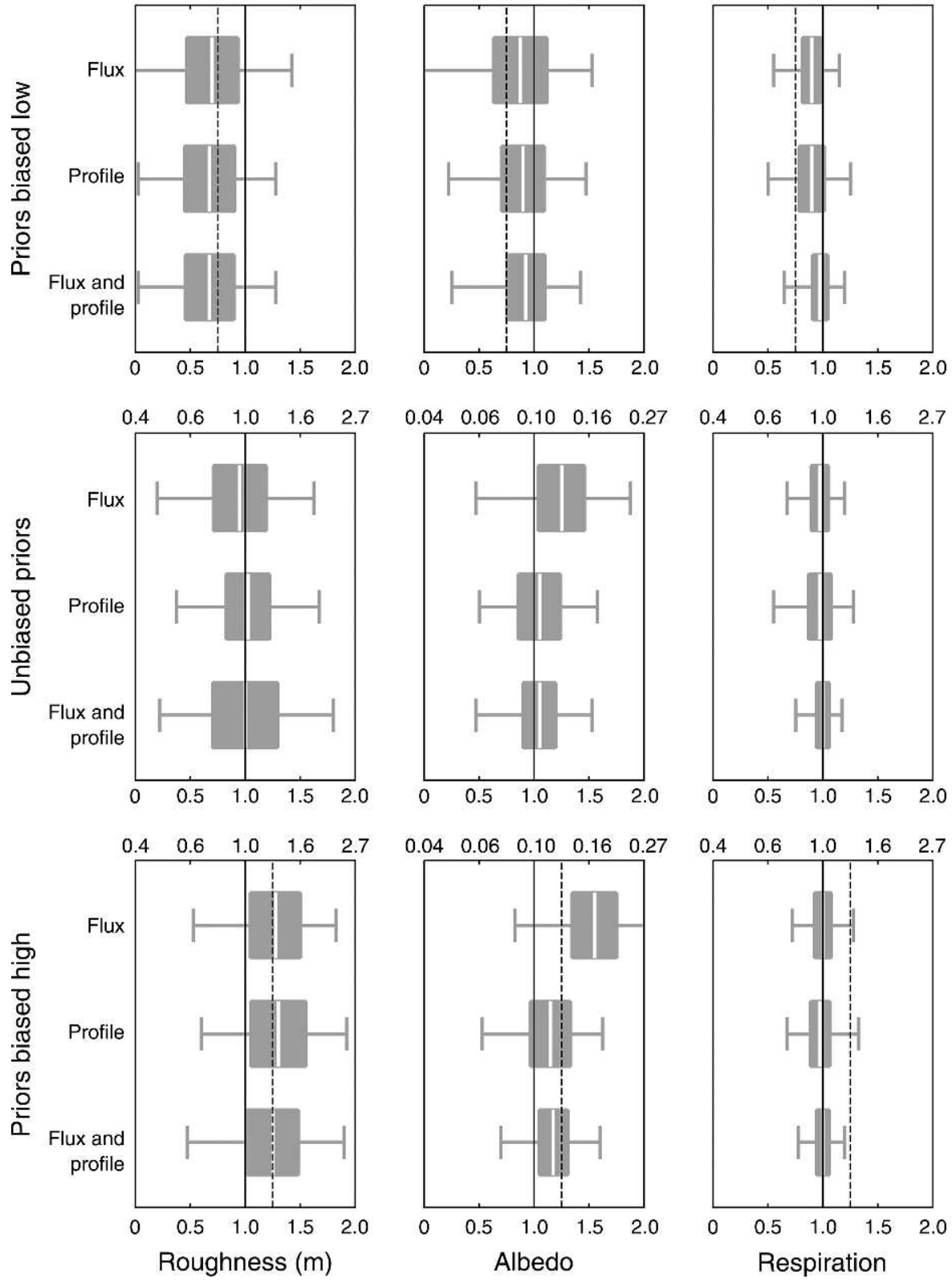

$\begin{array}{lllll}0.04 & 0.06 & 0.10 & 0.16 & 0.27\end{array}$
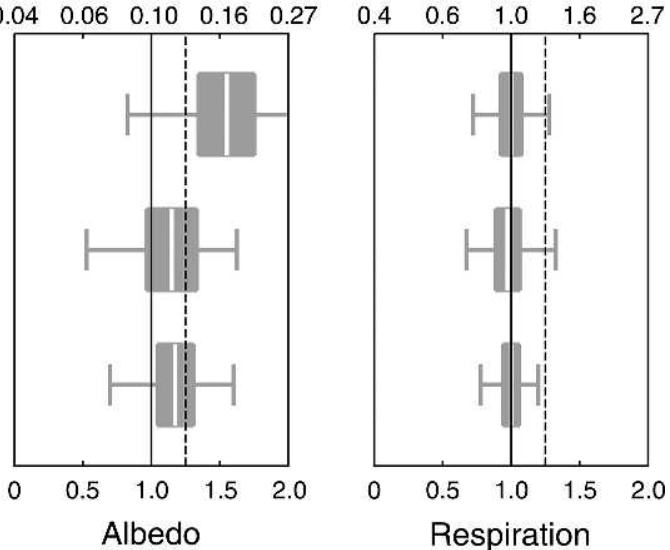

FIG. 5. Continued.

result, combined with the very low measured fluxes during these periods, suggests the presence of katabatic flows or uncorrected storage terms in the eddy flux data rather than a serious deficiency in the model. However the problem does not affect the surface fluxes during the daytime growth of the PBL. The results show that, when properly parameterized from measurements, processes encapsulated in the biosphere model are largely consistent with observations, albeit with less variation. Although in the NSA the weighted flux towers only accounted for $54 \%$ of the area (SSA $87 \%$ ), the weighted flux average for the SSA and NSA are close to the fluxes from just the OBS site. This congruence suggests that despite the spatial heterogeneity the of the study areas the simulations captured the aggregated response of the NSA and SSA for this period. This assumption is supported by the assertion that black spruce dominates the PBL dynamics of the region (Betts et al. 2001). Therefore we conclude that the surface components of the $\mathrm{CAB}$ model are capable of adequately simulating these aggregated landscape responses.

Comparisons of the $\mathrm{CAB}$ model to PBL observations are less robust due to the small number of available PBL soundings at the sites. This data sparsity means that only 
the midday period can be compared, and only for two days with suitable atmospheric conditions. Fortunately this is a period of seasonally and diurnally strong land surface exchanges and so sees active changes to the PBL. For the two days that are suitable, the $\mathrm{CAB}$ model performs well in capturing the evolution of key features in the PBL, such as the mean scalar properties of the mixed layer and the height of the boundary layer. However, whilst the study days and study site have been chosen to minimize the effect of advection, it is reasonable to assume that advection is having an unquantified and potentially significant impact on the PBL profile measurements and thus complicates the comparison with $\mathrm{CAB}$ predictions. Although the available data have not permitted an exhaustive test of the model, we have shown CAB to be suitably skilful. This skills justifies the follow-on application of the coupled model to investigate the information contained within PBL profiles above the land surface, in the stage 2 twin study.

In stage 2, two separate analyses were run using the Bayesian inversion scheme. The first, with flat a priori information, investigated the data content of the PBL and/or EC measurements. The second analysis looked at the ability of the inverted PBL and EC observations to correct biased a priori information. An advantage of using synthetic data to run these analyses is that the 'truth' is known exactly and so the retrieved states can be appropriately analyzed.

In first inversion, with flat, non-informative, a priori, we explored the theoretical limits of what inverting the observations can tell us about our parameters, i.e., the data resolution. The flat a priori experiment showed the inversion could return the correct (within uncertainties) estimates for LAI, foliar nitrogen, albedo and the respiration gain factor for all combinations of data (EC only, PBL profile only, both combined). However of these parameters, foliar nitrogen and albedo had poorly constrained posteriori distributions. Additionally the posteriori distributions for plant hydraulic conductance and the surface roughness length were largely undetermined apart from a one sided threshold. The strong constraints on LAI were expected; LAI has a strong impact on energy partitioning, evapotranspiration, and photosynthesis, and so can be constrained by all of the observations. Respiration is the only other factor needed to obtain NEE from GPP, and thus respiration gain is well constrained as a direct consequence of the constraints on LAI. These results mean that, theoretically at least, we might be able to determine the LAI and respiration of a landscape using an inversion of atmospheric profile data. However, due to the nature of the respiration gain factor, caution is required when applying this result generally to inverting respiration models as this information might not directly translate to constraints on actual respiration processes (such as temperature sensitivity). To capture these responses longer time series would be required.
In the second-inversion analysis, the addition of unbiased a priori parameters helps address this perceived lack of information and returns posteriori medians that were all (but one) within one standard deviation of the truth synthetic value (Fig. 5). However closer inspection reveals that posteriori distributions for foliar nitrogen and roughness contain very little information in addition to the information provided in the a priori. To a lesser extent this is also true with conductance and albedo. This low information content is in agreement with the findings of the flat a priori experiment. The biased inversions also backup this finding, indicating that the inversions can correct poor LAI and respiration a priori quite well. Biases in the conductance and albedo a priori were also partially amended, but biased a priori foliar nitrogen and roughness information was not improved.

Interestingly, the performance of inverting flux data and profile data was similar and only slightly worse than inverting both data sources. This result suggests that, at least in this synthetic study, the half hourly flux data does not have significantly different information content to the scalar concentrations within the PBL over 24 hours. This result is possibly due to the better constraints of the three scalars in the PBL (versus two fluxes) being balanced by the addition of the temporal constraints of eddy covariance flux data. However additional studies will have to be undertaken to generalize these findings to real world data sets, as relative uncertainties and biases will have a large effect. In particular, eddy flux data spanning many years is generally available, but can only normally be assumed to be representative of the immediate flux footprint $\left(\sim 1 \mathrm{~km}^{2}\right)$. Whereas PBL profiles are representative of a wider area but are impractical for capturing seasonal variability (with the possible exception of satellite derived products). Additionally, real-world errors and biases with both PBL (e.g., advection, poor model representation of stable PBLs [Cuxart et al. 2006]) and eddy covariance (e.g., katabatic flows [Kutsch et al. 2008]) will complicate the analysis (Lasslop et al. 2008).

This experiment only attempted to retrieve 6 out of a possible 42 parameters in the $\mathrm{CAB}$ model. Therefore the inversion implicitly assumes that these other 36 parameters were precisely "known." This is obviously not the case, because even when direct measurements are available for some parameters uncertainties remain. However an attempt to invert the PBL concentrations to retrieve information about a completely unknown system would be impractical as a 42-dimensional parameter space would be too vast to sample sufficiently with this approach and a more numerically efficient technique would be needed. Thus a question remains as to how these 36 additional parameters can be obtained for regions where direct measurements do not exist. 


\section{Conclusions}

Bottom-up (forward) modeling at the stand to PBL scale is, although far from perfected, a mature field. Given sufficient observations for model parameterization and initialization our ability to predict a small number of surface fluxes and scalars in the PBL is good. However our attempt to bridge the gap between the PBL and the stand scale has highlighted some fundamental limitations. Our inversions show that it is possible to resolve a few parameters and (theoretically) these can be determined from inversions. These parameters are typically those that are constrained by more than one scalar PBL measurement or EC flux measurement. Additionally, in the case of synthetic data, inverting flux time series and PBL concentrations provide similar constraints. This result means that there is potential to assimilate the diurnal changes of these PBL observations into ecosystem models, to improve and constrain them. However significant challenges remain if we are to apply this approach in a robust manner to real world heterogeneous data, where the inversion would be significantly complicated by the multiple land surface types.

An alternative point of view is to see the inversion as a "razor" allowing us to determine which parameters are important from the perspective of a coupled atmosphere-biosphere at the landscape scale. In fact it might be the case that we just need to determine if a parameter is below/above a threshold, and is therefore a controlling factor, or not, for a given ecosystem. Care will have to be taken when extending these findings beyond boreal black spruce, as it is very likely that the important parameters and thresholds will change with location, species, ecosystem stresses and timescales.

\section{Acknowledgments}

The authors thank Paul Jarvis and Shaun Quegan for their helpful comments and support during the drafting of this paper and also two anonymous reviewers whose comments were very helpful in developing this paper. T. C. Hill was funded by a NERC Studentship at the Centre for Terrestrial Carbon Dynamics.

\section{Literature Cited}

Anderson, D. W. 2000. Soils of tower sites in the Southern Study Area. In J. Newcomer, et al., editors. Collected data of the boreal ecosystem-atmosphere study. CD-ROM. NASA, Oak Ridge National Laboratory, Oak Ridge, Tennessee, USA.

Baldocchi, D., et al. 2001. FLUXNET: a new tool to study the temporal and spatial variability of ecosystem-scale carbon dioxide, water vapor, and energy flux densities. Bulletin of the American Meteorological Society 82:2415-2434.

Barr, A. G., A. K. Betts, R. L. Desjardins, and J. I. MacPherson. 1997. Comparison of regional surface fluxes from boundary-layer budgets and aircraft measurements above boreal forest. Journal of Geophysical ResearchAtmospheres 102:29213-29218.

Bayes, T. 1763. An essay towards solving a problem in the doctrine of chances. Philosophical Transactions 53:370-418.

Betts, A. K., and J. H. Ball. 1997. Albedo over the boreal forest. Journal of Geophysical Research-Atmospheres 102:2890128909.
Betts, A. K., J. H. Ball, and J. H. McCaughey. 2001. Nearsurface climate in the boreal forest. Journal of Geophysical Research-Atmospheres 106:33529-33541.

Bousquet, P., P. Ciais, P. Peylin, M. Ramonet, and P. Monfray. 1999. Inverse modeling of annual atmospheric $\mathrm{CO}_{2}$ sources and sinks 1. Method and control inversion. Journal of Geophysical Research-Atmospheres 104:26161-26178.

Chen, J. M., P. M. Rich, S. T. Gower, J. M. Norman, and S. Plummer. 1997. Leaf area index of boreal forests: theory, techniques, and measurements. Journal of Geophysical Research-Atmospheres 102:29429-29443.

Cuxart, J., et al. 2006. Single-column model intercomparison for a stably stratified atmospheric boundary layer. BoundaryLayer Meteorology 118:273-303.

Deardorf, J. W. 1966. Counter-gradient heat flux in lower atmosphere and in laboratory. Journal of the Atmospheric Sciences 23:503-506.

Denning, A. S., I. Y. Fung, and D. Randall. 1995. Latitudinal gradient of atmospheric $\mathrm{CO}_{2}$ due to seasonal exchange with land biota. Nature 376:240-243.

Draxier, R. R., and G. D. Hess. 1998. An overview of the HYSPLIT_4 modelling system for trajectories, dispersion and deposition. Australian Meteorological Magazine 47:295308.

Ewers, B. E., S. T. Gower, B. Bond-Lamberty, and C. K. Wang. 2005. Effects of stand age and tree species on canopy transpiration and average stomatal conductance of boreal forests. Plant, Cell and Environment 28:660-678.

Gelman, A. 1995. Bayesian data analysis. Chapman and Hall, London, UK.

Goulden, M. L., B. C. Daube, S. M. Fan, D. J. Sutton, A. Bazzaz, J. W. Munger, and S. C. Wofsy. 1997. Physiological responses of a black spruce forest to weather. Journal of Geophysical Research-Atmospheres 102:28987-28996.

Goulden, M. L., J. W. Munger, S. M. Fan, B. C. Daube, and S. C. Wofsy. 1996. Measurements of carbon sequestration by long-term eddy covariance: methods and a critical evaluation of accuracy. Global Change Biology 2:169-182.

Gower, S. T., J. G. Vogel, J. M. Norman, C. J. Kucharik, S. J. Steele, and T. K. Stow. 1997. Carbon distribution and aboveground net primary production in aspen, jack pine, and black spruce stands in Saskatchewan and Manitoba, Canada. Journal of Geophysical Research-Atmospheres 102:2902929041.

Hall, F. G., D. E. Knapp, and K. F. Huemmrich. 1997. Physically based classification and satellite mapping of biophysical characteristics in the southern boreal forest. Journal of Geophysical Research-Atmospheres 102:2956729580.

Hill, T. C., M. Williams, and J. B. Moncrieff. 2008. Modeling feedbacks between a boreal forest and the planetary boundary layer. Journal of Geophysical ResearchAtmospheres 113:D15122.

Hollinger, D. Y., and A. D. Richardson. 2005. Uncertainty in eddy covariance measurements and its application to physiological models. Tree Physiology 25:873-885.

Holtslag, A. A. M., and A. P. Vanulden. 1983. A simple scheme for daytime estimates of the surface fluxes from routine weather data. Journal of Climate and Applied Meteorology 22:517-529.

Jarvis, P. G., J. M. Massheder, S. E. Hale, J. B. Moncrieff, M. Rayment, and S. L. Scott. 1997. Seasonal variation of carbon dioxide, water vapor, and energy exchanges of a boreal black spruce forest. Journal of Geophysical ResearchAtmospheres 102:28953-28966.

Jarvis, P. G., and J. B. Moncrieff. 2000. The CO2 exchanges of boreal black spruce forest. In J. Newcomer, et al, editors. Collected data of the boreal ecosystem-atmosphere study. CD-ROM. NASA, Oak Ridge National Laboratory, Oak Ridge, Tennessee, USA. 
Keeling, C. D., and M. Heimann. 1986. Meridional eddy diffusion model of the transport of atmospheric carbon dioxide. 2. Mean annual carbon cycle. Journal of Geophysical Research-Atmospheres 91:7782-7796.

Knorr, W., and J. Kattge. 2005. Inversion of terrestrial ecosystem model parameter values against eddy covariance measurements by Monte Carlo sampling. Global Change Biology 11:1333-1351.

Kutsch, W. L., O. Kolle, C. Rebmann, A. Knohl, W. Ziegler, and E. D. Schulze. 2008. Advection and resulting CO2 exchange uncertainty in a tall forest in central Germany. Ecological Applications 18:1391-1405.

Lasslop, G., M. Reichstein, J. Kattge, and D. Papale. 2008. Influences of observation errors in eddy flux data on inverse model parameter estimation. Biogeosciences 5:1311-1324.

Lin, J. C., C. Gerbig, S. C. Wofsy, A. E. Andrews, B. C. Daube, K. J. Davis, and C. A. Grainger. 2003. A near-field tool for simulating the upstream influence of atmospheric observations: the stochastic time-inverted Lagrangian transport (STILT) model. Journal of Geophysical ResearchAtmospheres 108(D16):4493.

Lin, J. C., C. Gerbig, S. C. Wofsy, A. E. Andrews, B. C. Daube, C. A. Grainger, B. B. Stephens, P. S. Bakwin, and D. Y. Hollinger. 2004. Measuring fluxes of trace gases at regional scales by Lagrangian observations: application to the $\mathrm{CO} 2$ budget and rectification airborne (COBRA) study. Journal of Geophysical Research-Atmospheres 109:D15304.

Loescher, H. W., B. E. Law, L. Mahrt, D. Y. Hollinger, J. Campbell, and S. C. Wofsy. 2006. Uncertainties in, and interpretation of, carbon flux estimates using the eddy covariance technique. Journal of Geophysical ResearchAtmospheres 111:D21S90.

Macatangay, R., T. Warneke, C. Gerbig, S. Korner, R. Ahmadov, M. Heimann, and J. Notholt. 2008. A framework for comparing remotely sensed and in-situ $\mathrm{CO}_{2}$ concentrations. Atmospheric Chemistry and Physics 8:2555-2568.

MacPherson, J. I., and R. L. Desjardins. 2000. Atmospheric boundary layer analyses from Canadian Twin Otter aircraft In J. Newcomer, et al. editors. Collected data of the boreal ecosystem-atmosphere study. CD-ROM. NASA, Oak Ridge National Laboratory, Oak Ridge, Tennessee, USA.

Mahrt, L., and H. Pan. 1984. A 2-layer model of soil hydrology. Boundary-Layer Meteorology 29:1-20.

Mailhot, J., and R. Benoit. 1982. A finite-element model of the atmospheric boundary-layer suitable for use with numerical weather prediction models. Journal of the Atmospheric Sciences 39:2249-2266.

Martins, D. K., C. Sweeney, B. H. Stirm, and P. B. Shepson. 2009. Regional surface flux of $\mathrm{CO}_{2}$ inferred from changes in the advected $\mathrm{CO}_{2}$ column density. Agricultural and Forest Meteorology 149:1674-1685.

Miller, J. R., H. P. White, J. M. Chen, D. R. Peddle, G. McDermid, R. A. Fournier, P. Shepherd, I. Rubinstein, J. Freemantle, R. Soffer, and E. LeDrew. 1997. Seasonal change in understory reflectance of boreal forests and influence on canopy vegetation indices. Journal of Geophysical Research-Atmospheres 102:29475-29482.

Mosegaard, K., and A. Tarantola. 1995. Monte-Carlo sampling of solutions to inverse problems. Journal of Geophysical Research-Solid Earth 100:12431-12447.

Nakane, K., T. Kohno, T. Horikoshi, and T. Nakatsubo. 1997. Soil carbon cycling at a black spruce (Picea mariana) forest stand in Saskatchewan, Canada. Journal of Geophysical Research-Atmospheres 102:28785-28793.

Newcomer, J., et al. 2000. Collected data of the boreal ecosystem-atmosphere study. NASA, Oak Ridge National Laboratory, Oak Ridge, Tennessee, USA.
Owen, K. E., et al. 2007. Linking flux network measurements to continental scale simulations: ecosystem carbon dioxide exchange capacity under non-water-stressed conditions. Global Change Biology 13:734-760.

Potter, C. S., J. T. Randerson, C. B. Field, P. A. Matson, P. M. Vitousek, H. A. Mooney, and S. A. Klooster. 1993. Terrestrial ecosystem production - a process model based on global satellite and surface data. Global Biogeochemical Cycles 7:811-841.

Priestley, C. H. B., and W. C. Swinbank. 1947. Vertical transport of heat by turbulence in the atmosphere. Proceedings of the Royal Society Series A 189:543-561.

Raupach, M. R., P. J. Rayner, D. J. Barrett, R. S. DeFries, M. Heimann, D. S. Ojima, S. Quegan, and C. C. Schmullius. 2005. Model-data synthesis in terrestrial carbon observation: methods, data requirements and data uncertainty specifications. Global Change Biology 11:378-397.

Rayment, M. B., D. Loustau, and P. G. Jarvis. 2002. Photosynthesis and respiration of black spruce at three organizational scales: shoot, branch and canopy. Tree Physiology 22:219-229.

Running, S. W., D. D. Baldocchi, D. P. Turner, S. T. Gower, P. S. Bakwin, and K. A. Hibbard. 1999. A global terrestrial monitoring network integrating tower fluxes, flask sampling, ecosystem modeling and EOS satellite data. Remote Sensing of Environment 70:108-127.

Savage, K., T. R. Moore, and P. M. Crill. 1997. Methane and carbon dioxide exchanges between the atmosphere and northern boreal forest soils. Journal of Geophysical Research-Atmospheres 102:29279-29288.

Saxton, K. E., W. J. Rawls, J. S. Romberger, and R. I. Papendick. 1986. Estimating Generalized Soil-Water Characteristics from Texture. Soil Science Society of America Journal 50:1031-1036.

Sellers, P. J., et al. 1997. BOREAS in 1997: experiment overview, scientific results, and future directions. Journal of Geophysical Research-Atmospheres 102:28731-28769.

Troen, I., and L. Mahrt. 1986. A simple model of the atmospheric boundary layer sensitivity to surface evaporation. Boundary-Layer Meteorology 37:129-148.

Williams, M., B. E. Law, P. M. Anthoni, and M. H. Unsworth. $2001 a$. Use of a simulation model and ecosystem flux data to examine carbon-water interactions in ponderosa pine. Tree Physiology 21:287-298.

Williams, M., E. B. Rastetter, D. N. Fernandes, M. L. Goulden, S. C. Wofsy, G. R. Shaver, J. M. Melillo, J. W. Munger, S. M. Fan, and K. J. Nadelhoffer. 1996. Modelling the soil-plant-atmosphere continuum in a Quercus-Acer stand at Harvard forest: the regulation of stomatal conductance by light, nitrogen and soil/plant hydraulic properties. Plant, Cell and Environment 19:911-927.

Williams, M., E. B. Rastetter, G. R. Shaver, J. E. Hobbie, E. Carpino, and B. L. Kwiatkowski. 2001b. Primary production of an arctic watershed: an uncertainty analysis. Ecological Applications 11:1800-1816.

Williams, M., P. A. Schwarz, B. E. Law, J. Irvine, and M. R. Kurpius. 2005. An improved analysis of forest carbon dynamics using data assimilation. Global Change Biology 11:89-105.

Wofsy, S. C., M. L. Goulden, B. C. Daube, J. W. Munger, S. M. Fan, D. J. Sutton, and A. Bazzaz. 2000. Eddy correlation flux measurements of $\mathrm{CO} 2$ for BOREAS. In $\mathbf{J}$. Newcomer, et al., editors. Collected data of the boreal ecosystem-atmosphere study. CD-ROM. NASA, Oak Ridge National Laboratory, Oak Ridge, Tennessee, USA. 
APPENDIX A

Gap filling the meteorological data (Ecological Archives A021-068-A1).

\section{APPENDIX B}

The inversion scheme (Ecological Archives A021-068-A2). 